\title{
How to update design floods after the construction of small reservoirs and check dams: A case study from the Daqinghe river basin, China
}

\author{
Jianzhu Li*, Huafeng Sun and Ping Feng \\ State Key Laboratory of Hydraulic Engineering Simulation and Safety, Tianjin University, Tianjin 300072, China. \\ ${ }^{*}$ Corresponding author. e-mail: lijianzhu@tju.edu.cn
}

Several small reservoirs and a large number of check dams had been constructed in the Wangkuai reservoir watershed after 1970s, and flood time series lacked stationarity, which affected the original design flood hydrographs for the Wangkuai reservoir. Since the location, storage capacity and drainage area of the large number of check dams were unknown, we present a method to estimate their total storage capacities (TSC) and total drainage areas (TDA) by using the recorded rainstorm and flood data. On the basis of TSC and TDA, the flood events which occurred in an undisturbed period were reconstructed under current conditions to obtain a stationary flood series. A frequency analysis was subsequently performed to assess the design flood peak and volume for both small and medium design floods with a 10-200 year return period. For large and catastrophic floods, it was assumed that the upstream check dams and small reservoirs would be destroyed, and water stored in these hydraulic structures were re-routed to the Wangkuai reservoir by unit hydrograph. The modified flood peak and volume decreased for floods with a 10-200 year return period when compared to the current design flood. But for large design floods with a return period exceeding 500 years, peak discharge increased. This study provides a new method for design flood calculation or modification of the original design flood in watersheds with a large number of check dams.

\section{Introduction}

Land use and land cover changes have affected hydrological processes in many parts of the world, and because flood generation mechanisms have been altered with changes in land use, flood magnitude has either been intensified due to urban expansion, or mitigated by forestation (Archer and Newson 2002; Robinson et al. 2003; Nirupama and Simonovic 2007). Many studies have focused on the effects of land use change on flood events (Niehoff et al. 2002; Costa et al. 2003; Ott and Uhlenbrook 2004). Results showed that land use/land cover change had a significant effect on flood peak and volume for medium and small flood events, and that the effect became relatively small with flood magnitude increase. In fact, Zhang and Mao (2012) pointed out that the effects of land use change on floods with 1000-year return periods or greater could be neglected.

Due to land use change, the conditions of occurrence of data samples or the statistical characteristics (e.g., mean and variance) of data have changed over time, and the assumption of independent and identical distribution of flood extreme values breaks down (Milly et al. 2008). Hence, the design flood hydrograph derived under the assumption of stationarity for hydraulic structures should be updated.

Generally, there are two methods to modify design floods due to environmental change. One

Keywords. Non-stationarity; hydraulic structures; design flood hydrograph; storage capacity and drainage area. 
method is non-stationary frequency analysis using observed flood data directly. Frequency analysis of a non-stationary time series requires a different approach than the conventional stationary one because the distribution parameters and the distribution itself change in time, as do the estimates of exceedance probability and associated uncertainty of a design value of interest. Thus, any evidence of departure from the basic assumptions of independence and stationarity of observations could significantly affect the validity of frequency analysis results (Cox et al. 2002; Cunderlik and Burn 2003; Gilroy and McCuen 2012). Frequency analysis with covariates (Cox et al. 2002; Katz et al. 2002), time-varying moments (Strupczewski et al. 2001a, b) and quantile regression methods (Yu and Moyeed 2001; Yu et al. 2003) were presented to adapt to non-stationarity of the hydrological time series, and were reviewed by Khaliq et al. (2006). Another strategy is to reconstruct flood events under current land use and land cover conditions either by statistical methods or by a hydrological model simulation, and then make frequency analysis using the reconstructed flood series. Zhang and Mao (2012) reviewed the commonly used methods of reconstructing historical flood extremes under current land use and land cover conditions, and they pointed out that rainfall intensity-flood peak curves and hydrological model simulations were the most popular methods. However, little had been done to update the design flood hydrograph.

Many dams have been built worldwide and, aside from forestation/deforestation, they have triggered changes in hydrological regimes downstream (Zahar et al. 2008). Dams impact river hydrology through changes in the timing, magnitude, and frequency of low and high flows, ultimately producing a hydrologic regime differing significantly from the preimpoundment natural flow regime. Some methods have been presented to quantify the effects of dams on hydrological regimes. The simplest one was the comparison between the regulated and unregulated sites. Zimmerman et al. (2010) determined the effects of dams on sub-daily variation in river flows for multiple sites across a large watershed by this method. Magilligan and Nislow (2005) assessed hydrological changes associated with dams by a hydrological model, supplemented with orientation statistics for some hydrograph parameters. Multivariate statistical analysis was used by Matteau et al. (2009) to assess the hydrologic impact of dams. They first applied principal component analysis in order to select the hydrologic variables most affected by dams, and then applied canonical correlation analysis to determine the factors that influence the extent of the hydrologic change experienced by each hydrologic variable downstream from dams. To assess the hydrologic impact of dams on flood flows throughout the United States, regional regression models of the median annual 1-day maximum flow were developed by Fitzhugh and Vogel (2010) as a function of natural watershed characteristics, dam storage, and population density.

However, most of the researches were focused on the variations in hydrological regimes caused by dams for ecological and morphological purposes (Wellmeyer et al. 2005; Lajoie et al. 2007; Hsieh et al. 2013). The hydrological responses had not been understood clearly in watersheds with a large number of check dams and small hydraulic structures such as the Wangkuai reservoir watershed, Daqinghe river basin in China. Despite the large number of check dams, the hydrological responses have not been the focus of prior research, and their impact on the hydrological cycle is only beginning to be understood. As stated by Smith et al. (2002), the extent of small artificial impoundments and their impact on the hydrological cycle is becoming better appreciated.

In the Wangkuai reservoir watershed, there are more than 6000 check dams, but observations of check dams are difficult to obtain, because they were constructed at the request of the residents without any long-term design schemes. The locations, storage capacities and outflow methods have not been inventoried or documented. Thus, the preceding studies in this watershed did not consider the impact of the check dams on hydrological processes, but made a direct analysis using the recorded hydrological data at the Wangkuai reservoir. Based on the detected change point in 1979, Feng et al. (2013) recalculated the design floods for Wangkuai reservoir by mixed distribution of flood peak time series, and concluded that the design flood peak and volume of any return period became smaller. Feng and Li (2013) confirmed this result using the Copula method. However, the study did not take dam break of the upstream check dams or hydraulic structures for low frequency flood events into account, both of which may lead to flood peak increase.

Since non-stationarity in flood series have been identified in the Wangkuai reservoir watershed ( $\mathrm{Li}$ 2013), the objective of this study is to update the design floods with low and high frequency, respectively, by considering the impacts of check dams and small reservoirs on flood processes. This work could provide a new method for design flood calculation in watersheds with large number of check dams.

\section{Study area}

The Wangkuai reservoir, located in upstream Sha River, Daqinghe river basin (figure 1), was selected 


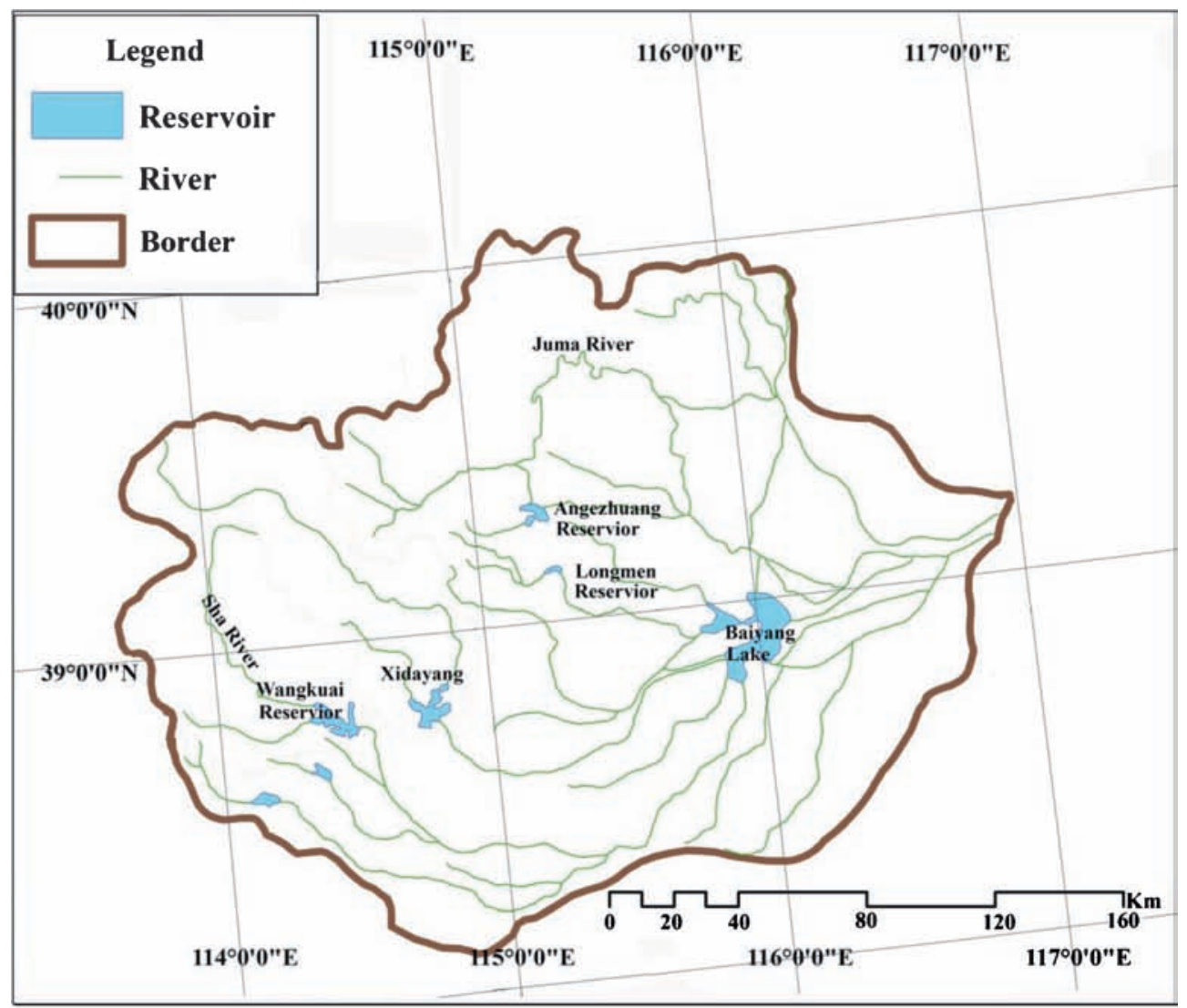

(a)

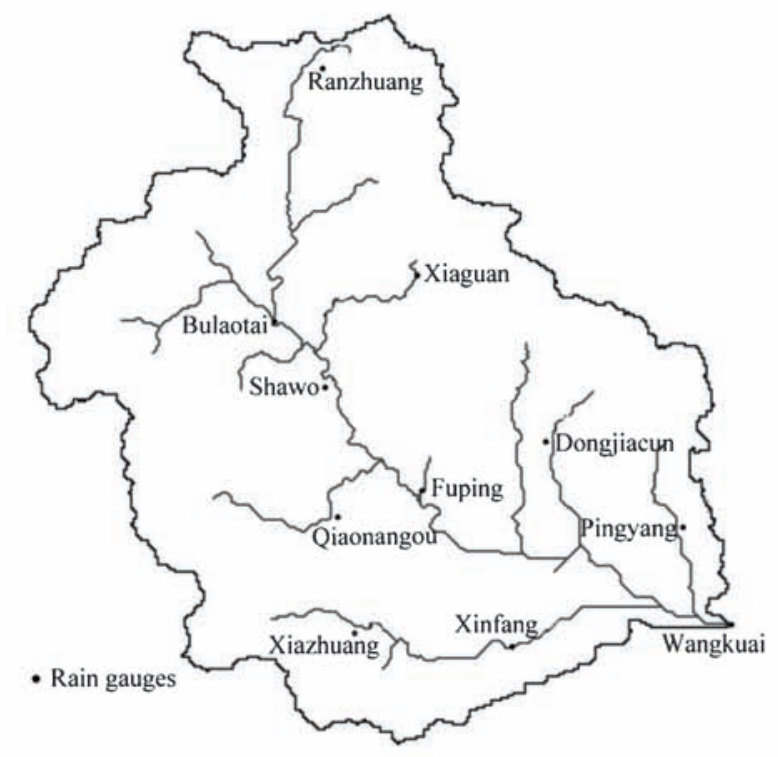

(b)

Figure 1. The study area and locations of rain gauges. (a) Daqinghe river basin and (b) the Wangkuai reservoir watershed and rain gauges distribution.

as the study area. Construction of the Wangkuai reservoir began in June 1958 and was completed in September 1960. The reservoir was built for the purposes of flood control, irrigation and electric power generation. The reservoir controls a drainage area of $3770 \mathrm{~km}^{2}$, and the storage capacity is $13.89 \times 10^{8} \mathrm{~m}^{3}$. The design floods currently in use (table 1) were calculated under the assumption of stationarity using recorded flood data from 1956 to 1985 . 
The watershed receives $600 \mathrm{~mm}$ of precipitation on average, mostly in summer (70-80\%). The annual mean temperature is $7.4^{\circ} \mathrm{C}$. The watershed is characterized by steep slopes and bedrock outcrops. Forest and grass are dominant on the hill slopes. Urban area is $<2 \%$. Rainfall and runoff data have been monitored for a period of more than 50

Table 1. Currently used design floods for Wangkuai reservoir.

\begin{tabular}{ccrrr}
\hline \multirow{2}{*}{$\begin{array}{c}\text { Return } \\
\text { period }(\mathrm{yr})\end{array}$} & $\begin{array}{c}\text { Peak discharge } \\
\left(\mathrm{m}^{3} / \mathrm{s}\right)\end{array}$ & \multicolumn{3}{c}{ Volume $\left(10^{8} \mathrm{~m}^{3}\right)$} \\
\cline { 3 - 5 } & 31436 & $1 \mathrm{~d}$ & $3 \mathrm{~d}$ & $6 \mathrm{~d}$ \\
\hline 10000 & 28345 & 17.10 & 28.62 & 34.00 \\
5000 & 21301 & 12.90 & 21.70 & 26.00 \\
1000 & 18344 & 11.10 & 18.80 & 22.70 \\
500 & 14530 & 8.06 & 14.05 & 16.81 \\
200 & 11741 & 6.40 & 11.29 & 13.68 \\
100 & 9062 & 4.82 & 8.65 & 10.67 \\
50 & 5766 & 2.90 & 5.41 & 6.93 \\
20 & 3550 & 1.66 & 3.25 & 4.37 \\
10 & & & & \\
\hline
\end{tabular}

Table 2. The main small reservoirs on the upstream of Wangkuai reservoir.

\begin{tabular}{lccc}
\hline $\begin{array}{l}\text { Small } \\
\text { reservoir }\end{array}$ & $\begin{array}{c}\text { Storage } \\
\text { capacity }\left(10^{4} \mathrm{~m}^{3}\right)\end{array}$ & $\begin{array}{c}\text { Year of } \\
\text { being built }\end{array}$ & $\begin{array}{c}\text { Drainage } \\
\text { area }\left(\mathrm{km}^{2}\right)\end{array}$ \\
\hline Haiyan & 367.0 & 1979 & 12.3 \\
Mapeng & 45.0 & 1996 & 52.0 \\
Tagou & 10.0 & 1978 & 5.5 \\
Dahewan & 4.0 & 1981 & 33.1 \\
Duizigou & 14.0 & 1975 & 1.2 \\
Shijia & 22.0 & 1973 & 9.8 \\
Waquangou & 12.0 & 1974 & 1.8 \\
Yujiatai & 10.2 & 1975 & 5.7 \\
\hline
\end{tabular}

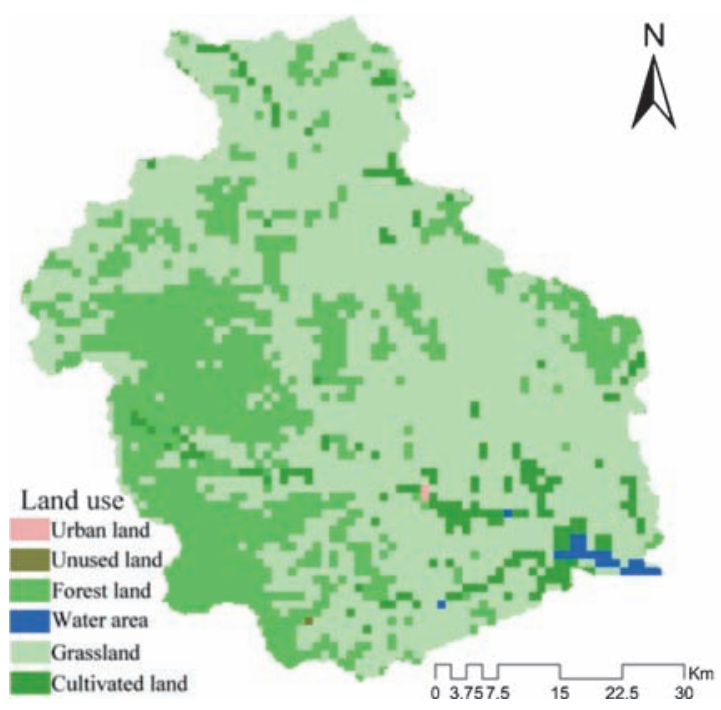

(a) 1980 land use. years from 1956 to 2008 . There are 11 rain gauges available in the study area.

Soil erosion is serious in this watershed, so soil and water conservation was carried out from the 1980s, during which time check dams became dominant. More than 6000 check dams were built from 1980 to 2008 , but the storage capacity could not be derived. Additionally, there are eight small reservoirs and six of them were built in the 1970s (table 2). Their total storage capacity was up to $484.2 \times 10^{4} \mathrm{~m}^{3}$. Haiyan reservoir, whose design criterion is to withstand floods with a 500-year return period, has the largest storage capacity of $367 \times 10^{4} \mathrm{~m}^{3}$. There were also ponds and retaining dams with effective storage capacity of $148 \times$ $10^{4} \mathrm{~m}^{3}$. Figure 2 showed the land use change using remotely sensed data from 1980 and 2000. Comparing the land use data of 2000 with 1980, land use remained almost invariant. So the main factors affecting flood processes were upstream small hydraulic structures and the large number of check dams in this watershed.

\section{Data and methods}

\subsection{Data}

The rainstorm and flood data were provided by the Hydrology and Water Resources Survey Bureau of Hebei Province. Rainfall data used in this study are measured from 11 stations and the mean rainfall was calculated by the Theissen polygon method. A water balance equation was employed to calculate inflow flood data of the Wangkuai reservoir using the reservoir water level and the discharge data.

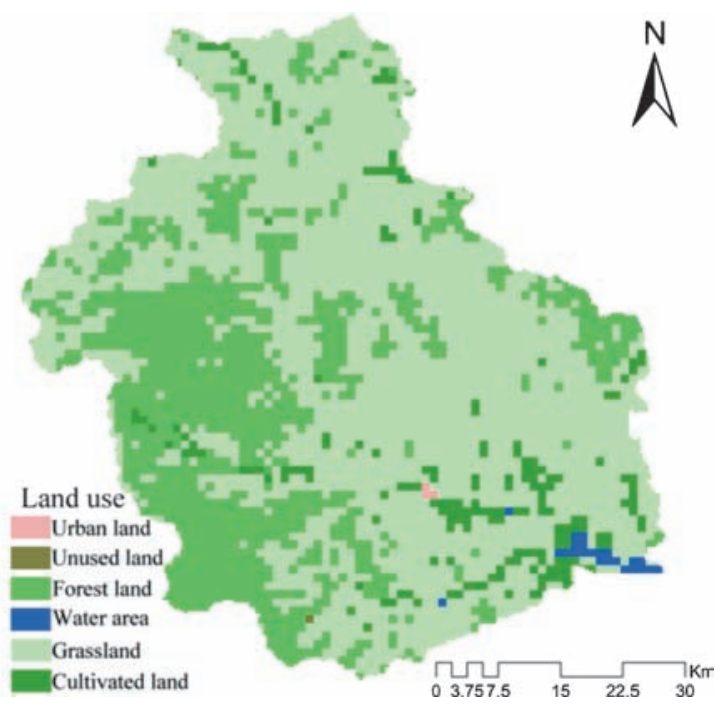

(b) 2000 land use.

Figure 2. Remotely sensed land use of the Wangkuai reservoir watershed. 
Table 3. The area of each land use in 1980 and 2000.

\begin{tabular}{lrrrrr}
\hline & \multicolumn{2}{c}{1980} & & \multicolumn{2}{c}{2000} \\
\cline { 2 - 3 } \cline { 5 - 6 } Land use & Area $\left(\mathrm{km}^{2}\right)$ & Percent $(\%)$ & & Area $\left(\mathrm{km}^{2}\right)$ & Percent (\%) \\
\hline Agricultural land & 247.9 & 6.58 & & 250.3 & 6.64 \\
Forest land & 1099.2 & 29.16 & & 1096.4 & 29.08 \\
Grassland & 2391.0 & 63.42 & & 2389.2 & 63.37 \\
Water area & 29.2 & 0.77 & & 30.1 & 0.80 \\
Urban & 1.9 & 0.05 & & 3.1 & 0.08 \\
Unused land & 0.8 & 0.02 & & 0.9 & 0.02 \\
\hline
\end{tabular}

The time series are from 1956 to 2008, and the data was collected on an hourly basis.

The remotely sensed land use data of 1980 and 2000 were provided by the Chinese Academy of Science. The land use was classified into six types: forest, grassland, agricultural land, urban area, water area and unused land. The area of each land use was derived in GIS software and is shown in table 3. It was found that they remained almost invariant from 1980 to 2000.

\subsection{Method}

To update the design flood, the recorded flood series during the undisturbed period were reconstructed under current land use conditions to form stationary flood series, and frequency analysis was carried out for small and moderate design floods. For large and catastrophic design floods, destruction of upstream check dams and small reservoirs were accounted for. The total storage capacity (TSC) and total drainage area (TDA) of upstream small reservoirs and check dams were key components in the calculation of both small and large design floods. However, the check dams were built without long-term design, and both the locations and storage capacities were not known. So a new method is proposed to estimate the total storage capacities and drainage areas of upstream small reservoirs and check dams with no field data.

\subsubsection{How to estimate the TSC with no field data available?}

For dams with upstream and downstream hydrological stations, a comparison could be done for each flood process between the upstream and downstream gauging stations to quantify the impact of dams on flood characteristics (Graf 2006; Onema et al. 2006). Matteau et al. (2009) showed several explanatory factors for changes in hydrological variables, including some factors relating to the dam characteristics: the maximum storage capacity of nearest upstream reservoir $(\mathrm{CM})$ and the cumulative maximum storage capacity of all upstream reservoirs (CCM). These indices of the dam should be calculated on the premise that the storage capacity and drainage area of the dam were known. However, there are more than 6000 check dams and no upstream hydrological station for the Wangkuai reservoir watershed. Therefore, we propose a new method to estimate the total storage capacity of the check dams.

The method uses observed historical rainstorm and flood data. Two similar heavy rainstorms (similar total rainfall depth, intensity, duration and spatial distribution) during pre- and post-1979 periods were selected, and should generate similar flood processes and fill up the upstream small reservoirs and check dams. Compared with the two flood processes, the difference between the surface runoff of the two flood events is the total storage capacity of the small reservoirs and check dams.

In this method, there are several assumptions: (1) the selected rainstorm pairs share the same characteristics, i.e., the same rainfall amount and the same temporal and spatial distributions; (2) the antecedent precipitation amount for the selected rainstorm pairs is the same; and (3) no water was stored in the upstream check dams prior to the rainstorms and the check dams were filled up after the rainstorms.

However, the occurrence of the same rainstorms in a watershed may be impossible, especially in a watershed with short flood records. In Wangkuai reservoir watershed, only five large flood events occurred, which were in 1956, 1963, 1964, 1996 and 2000. Therefore, there was a limited amount of flood data that could be used for estimation of TSC with respect to assumptions (1) and (2). If the selected rainstorms were too small to fill up all the check dams and small reservoirs, TSC would be underestimated. As for assumption (3), it is not necessary for all the check dams and small reservoirs to be empty, for their functions of irrigation, reaction, etc., which may result in underestimation in TSC.

If no similar heavy rainstorms existed in predisturbed and disturbed periods, rainfall and runoff relations could be employed to estimate the total storage capacities. All flood events should be included to establish the rainfall and runoff 

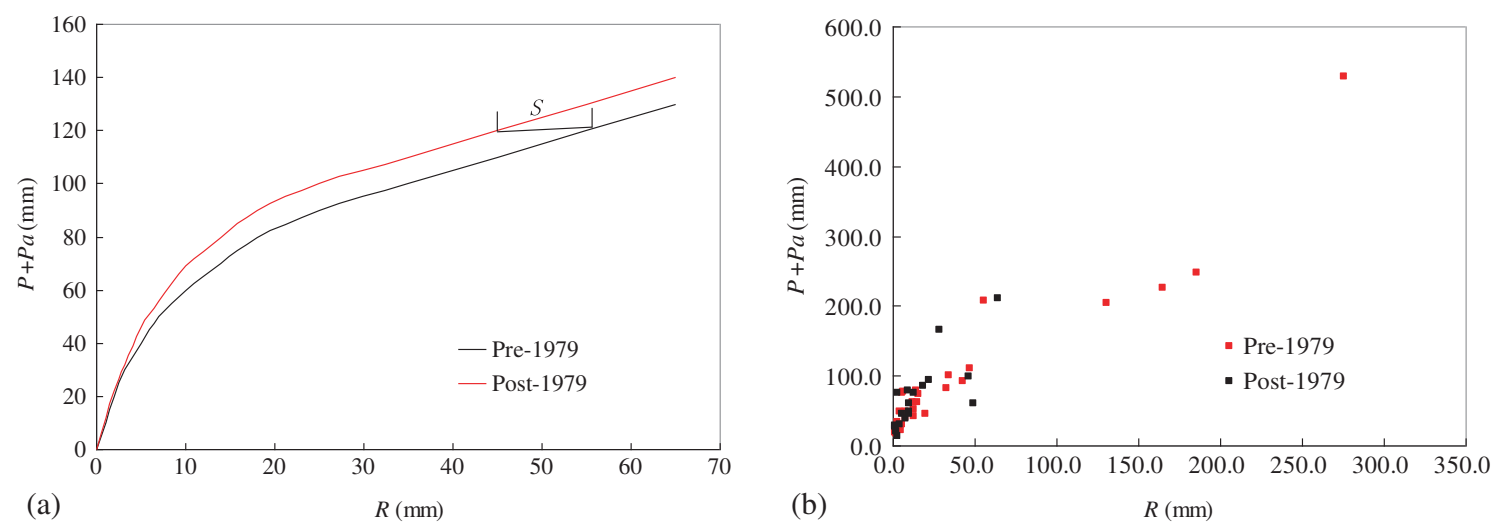

Figure 3. The estimation scheme of TSC by rainfall and runoff relation.

relations pre- and post-1979, respectively. The upper tails of the two lines are parallel, which means that soil moisture reaches its maximum. Considering the same rainfall amount in the upper tail, the difference of the corresponding runoff could be assumed to be TSC (figure 3).

There are two assumptions for this method: (1) saturation excess runoff generation was dominant in this watershed, and runoff was closely related with total rainfall amount, but not with rainfall intensity; (2) the areal average rainfall amount was used, and it was assumed that rainfall was distributed uniformly spatially. But saturation excess and infiltration excess runoff generation may be concurrent, especially in semi-arid and semi-humid climate zones. There exists uncertainty for the calculated TSC due to the fitted unreliable rainfall runoff relations.

It is simple to use the former method, but difficult to select two identical heavy rainstorms. The advantage of the first method is that it can be used in any climate zone. For the latter, abundant rainfall and flood data are used, and is easily achieved. But in arid regions it cannot be applied due to the poor relationship between rainfall and runoff. The relationship between precipitation and flood volumes is plotted in figure $3(\mathrm{~b})$. As can be seen, the plots scatter disorderly and we can not draw a curve as in figure 3(a). Therefore, the first method is adopted.

\subsubsection{How to estimate TDA with no data available?}

Since there are a large number of check dams, we could not derive the drainage area of each one to total them. A new method was proposed to estimate TDA by using recorded rainstorm and flood data.

Consider all the upstream check dams and small reservoirs as a whole, i.e., a theoretical reservoir, which is of equal storage capacity and drainage area to the existing check dams and small reservoirs. When small flood events occur, the runoff generated in the theoretical reservoir watershed will be stored, which means the recorded flood process at the Wangkuai reservoir is contributed by the precipitation falling on the area $A-A_{r}(A$ is the area controlled by the Wangkuai reservoir, $A_{r}$ is the drainage area of the reservoir). For small scale area, peak discharge is proportional to the contributing area, but this law will be invalid at scales where the rainfall duration is less than the time to equilibrium (Ogden and Dawdy 2003). In this case, it was found that peak discharge follow Power-law scaling with drainage area (Gupta et al. 2007, 2010), which is dominated by the rainfallrunoff variability at smaller scales, whereas it is dominated by the drainage network structure and flow dynamics at larger scales. Tarolli et al. (2012) built a relationship between the unit discharge and catchment size and fitted an exponential function, which was attributed to scale effect. Ayalew et al. (2014) showed that the flood scaling parameters changed from event to event, and analyzed how the parameters were affected by catchment rainfall and physical variables by hydrologic simulation experiments. Therefore, it is difficult to determine the flood scaling parameters. Wang et al. (2000) found a linear relationship between design flood peak and catchment size in Nenjiang watershed using the results in 19 sub-catchments, which can be expressed by equation (1), and then the drainage area of the theoretical reservoir could be estimated.

$$
\frac{A-A_{r}}{A}=\frac{Q_{0}}{Q_{t}}
$$

where $A$ is the area controlled by the Wangkuai reservoir, $A_{r}$ is the drainage area of the theoretical reservoir, $Q_{0}$ and $Q_{t}$ are flood peaks at the Wangkuai reservoir affected and unaffected by the theoretical reservoir for the same flood event, respectively. In this method, rainfall is assumed to be uniformly distributed in the watershed, and 
flood peak has a linear relationship to watershed size, which means the unit discharge $\left(\mathrm{m}^{3} \mathrm{~s}^{-1} \mathrm{~km}^{-2}\right)$ remains invariant regardless of the watershed size.

However, $Q_{0}$ and $Q_{t}$ could not be measured for the same flood events, because $Q_{0}$ was measured after the change point 1979 , and $Q_{t}$ was measured before 1979. Therefore, we must present a new method to obtain $Q_{0}$ and $Q_{t}$ for some flood events. Since there exists a relationship between flood peak and rainfall intensity, we could obtain the value of $Q_{t}$ after 1979 by analyzing the changes in this relation pre- and post-1979. The specifics are as follows: (1) Several rainstorm and flood data during the undisturbed period were used, and 1-hr, 3-hr and 6-hr maximum rainfall intensities and the corresponding flood peak were selected for each flood event. (2) The relationship between maximum rainfall intensity in different time scales and the respective flood peak(s) was established, and equations could be fitted. (3) Several rainfall events during the disturbed period whose rainfall peak occurred in the beginning were selected, and the theoretical flood peak $Q_{t}$ could be calculated using the best fitted equation. The decreased flood peak due to small reservoirs and check dams is the difference between the theoretical flood peak $Q_{t}$ and observed flood peak $Q_{0}$.

It is necessary for the peak discharge to be closely related to rainfall intensity in a time scale. Additionally, the calculated TDA is affected by the selection of different rainstorms. Therefore, the mean of each TDA derived by different rainstorms is decided to be the final result.

\subsubsection{Calculation of design hydrographs}

A series of historical flow data over 20 years was adequate to represent the natural conditions (Richter et al. 1997). However, a series of flow data with at least 30 years is needed for flood frequency analysis in China. Genz and Luz (2014) thought the use of time series from different periods can result in discrepant representative flows, especially for the rivers of the semi-arid regions, where annual flows have shown high values of standard deviation. The assessment of hydrological changes resulting from human intervention in the catchment area must be referenced by a natural or pre-impact hydrological regime, which will be used to define periods and reference data. Since the recorded data in the pre-dammed (or reference) period are not adequate for flood frequency analysis in the Wangkuai reservoir, we have to reconstruct the natural flood processes in the reference period under current land cover conditions as follows.

Based on the TSC and TDA, we could estimate the effects of natural flood processes on design floods. Since there were no catastrophic floods in the recorded period, destruction of check dams was not accounted in the reconstruction of flood processes for the pre-1979 period. Based on the assumption of uniformly distributed rainfall and the linear relationship between discharge and catchment size, the surface discharge of the selected flood events during the pre-dammed period should be decreased by the proportion $A_{r} / A$ until all of the upstream reservoirs and check dams reach their storage capacities, provided that the surface discharge generated in $A_{r}$ area is greater than the storage capacity. If this latter condition does not hold, the surface runoff hydrograph should decrease by the proportion $A_{r} / A$ from the beginning to end. Subsequently, we derived the stationary flood series comprised of reconstructed pre-dammed floods and post-dammed floods.

Although the reconstructed flood series were stationary, low frequency design floods derived by frequency analysis made by them is not reliable for its neglect of destruction of check dams, resulting in lower design values. On the basis of Standard for Flood Control (The Ministry of Water Resources of the People's Republic of China, 1994), reservoirs with storage capacity of 100 1000 million $\mathrm{m}^{3}$ could withstand floods with 300 500 year return periods. Therefore, flood frequency analysis was made to calculate small and medium design floods.

For catastrophic floods with 1000-year or 10000year return periods, dam break for the upstream small reservoirs and check dams must be considered. To understand dam break floods, two approaches have been pursued. The first approach has sought to reconstruct characteristics of outburst floods from geological field evidence using empirical relationships (e.g., Walder and Costa 1996), palaeocompetence (Carrivick 2007) and various palaeohydraulic techniques including slope area methods. The second approach has been adopted from the engineering community and is the application of fluid dynamics computational models, both with and without the use of flume experiments. These studies are designed to develop simple physical-based equations that highlight the controls such as impounded water volume, reservoir geometry and dam height, for example, as well as to consider idealized dam breach evolution (Carrivick 2010).

However, in the Wangkuai reservoir watershed, the locations and the design criteria of the check dams were unknown, and the above two approaches could not be applied. A simple hydrological method should be developed. On the basis of the original design floods, the new design floods with larger return periods could be derived based on the following assumptions: (1) all the check dams and small reservoirs are destroyed when flood peaks occur; (2) all the water stored in the small 
reservoirs and check dams propagates to the Wangkuai reservoir by unit hydrograph, and adds to the original design flood, which forms the new design flood influenced by upstream small reservoirs and check dams. Assumption (1) is the worst condition among all the conditions which leads to larger peak discharge. For catastrophic flood events, peak discharge is large enough to destroy the small reservoirs and check dams, but the check dams might be destroyed before peak discharge at some time. However, we cannot determine the exact time when they are destructed, assumption (1) could simplify and quantify this problem. With regard to assumption (2), unit hydrograph is used to imply that runoff stored in check dams and small reservoirs are uniformly distributed in the watershed which is a limitation. Under this condition, the peak discharge will be influenced by selection of the unit hydrograph. Large floods produce high peak discharge of the unit hydrograph, and therefore the peak discharge of the calculated design floods with return periods greater than 1000 years would be lower if the unit hydrograph was calculated by recorded rainstorm and flood data, because the largest recorded flood occurred in 1963 was just about 100-year return period. Assumptions (1) and (2) taken together imply that the new design flood peak may be higher or lower than the theoretical one, but it is larger than the originally used. The results will provide contrary view with the traditional that hydraulic structures decrease design floods.

\section{Results and discussion}

\subsection{Estimation of TSC}

The flood events that occurred on August 12, 1964 and August 5, 1996 were selected to estimate the total storage capacity of the upstream small reservoirs and check dams. The August 12, 1964 rainfall events had a total rainfall amount of $132.4 \mathrm{~mm}$ with a maximum hourly rainfall intensity of $10.8 \mathrm{~mm} / \mathrm{hr}$, and the duration was $29 \mathrm{hr}$. The August 5, 1996 rainfall event had a total rainfall amount of $134.8 \mathrm{~mm}$ with a maximum rainfall intensity of $7.9 \mathrm{~mm} / \mathrm{hr}$, and the duration was $30 \mathrm{hrs}$. The other characteristics of the two rainfall events are listed in table 4 . We can see the characteristics of the two rainfall events are similar. The former rainfall event generated $39.19 \mathrm{~mm}$ surface runoff, while the latter generated $35.24 \mathrm{~mm}$ surface runoff, and the difference $3.95 \mathrm{~mm}$ is assumed to be stored by the small reservoirs and check dams upstream. Due to the large rainfall amount of the selected events, the small reservoirs and check dams were assumed to have reached their storage capacities, and thus $3.95 \mathrm{~mm}$ is the total storage capacity of the upstream hydraulic structures.

The estimated storage capacity $(3.95 \mathrm{~mm})$ equals to 14.89 million $\mathrm{m}^{3}$, larger than the total storage capacity $\left(7.39\right.$ million $\left.\mathrm{m}^{3}\right)$ of the small reservoirs. Because there were a large number of check dams upstream as well, the estimated total storage capacity of 14.89 million $\mathrm{m}^{3}$ was considered reasonable.

\subsection{Estimation of TDA}

We selected eight flood events during the undisturbed period (1956-1979) (table 5) to establish

Table 5. The selected flood events during undisturbed period.

\begin{tabular}{lcc}
\hline & $\begin{array}{c}\text { Maximum } \\
\text { 3-hr rainfall } \\
\text { Flood events }\end{array}$ & $\begin{array}{c}\text { Flood } \\
\text { intensity (mm) }\end{array}$ \\
\hline July 10, 1958 & peak m $^{3}$ \\
July 24, 1962 & 16.1 & 587.0 \\
August 7, 1963 & 13.3 & 655.6 \\
August 12, 1964 & 37.2 & 9036.4 \\
August 16, 1966 & 30.3 & 2875.5 \\
August 4, 1967 & 18.8 & 342.2 \\
June 25, 1971 & 21.2 & 1296.5 \\
August 14, 1973 & 16.4 & 341.0 \\
\hline
\end{tabular}

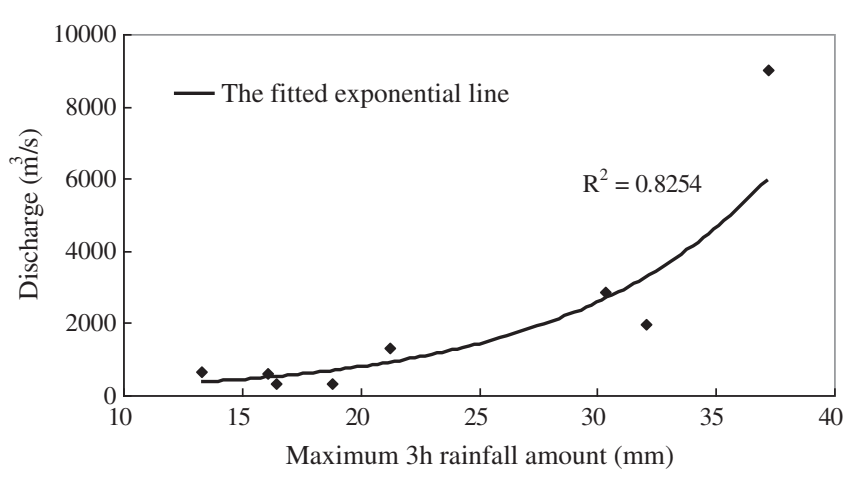

Figure 4. The relationship between rainfall intensity and flood peak.

Table 4. The characteristics of the selected rainfall events.

\begin{tabular}{lcccc}
\hline $\begin{array}{l}\text { Rainfall } \\
\text { events }\end{array}$ & $\begin{array}{c}\text { Rainfall } \\
\text { amount (mm) }\end{array}$ & Duration (hr) & $\begin{array}{c}\text { Maximum rainfall } \\
\text { intensity (mm) }\end{array}$ & $\begin{array}{c}\text { Antecedent } \\
\text { rainfall (mm) }\end{array}$ \\
\hline August 12,1964 & 132.4 & 29 & 10.8 & 76.2 \\
August 5, 1996 & 134.8 & 30 & 7.9 & 75.8 \\
\hline
\end{tabular}


Table 6. The selected flood events during disturbed period and the estimated Ar/A.

\begin{tabular}{lcccc}
\hline Flood events & $\begin{array}{c}\text { Maximum 3-hr } \\
\text { rainfall }(\mathrm{mm})\end{array}$ & $\begin{array}{c}\text { Observed } \\
\text { discharge }\left(\mathrm{m}^{3} / \mathrm{s}\right)\end{array}$ & $\begin{array}{c}\text { Calculated } \\
\text { discharge }\left(\mathrm{m}^{3} / \mathrm{s}\right)\end{array}$ & $\begin{array}{c}A_{r} / A \\
(\%)\end{array}$ \\
\hline July 22, 1989 & 20.3 & 553.0 & 820.1 & 32.6 \\
August 26, 1990 & 23.3 & 858.7 & 1267.0 & 32.2 \\
July 8, 1994 & 19.8 & 497.2 & 773.7 & 35.7 \\
August 18, 1999 & 15.5 & 291.8 & 468.9 & 37.8 \\
Mean & & & & 34.6 \\
\hline
\end{tabular}

the rainfall intensity-flood peak relation, since 1979 was found to be the significant change point for flood series. We found that the flood peak discharges had the closest relationship with the maximum 3-hr rainfall amount when compared to the 1-hr and 6-hr maximum. Equation (2) is the exponential function that was fitted to the data and the correlation coefficient $R^{2}$ was 0.8254 , as shown in figure 4 .

$$
Q_{t}=74.679 \exp \left(0.1179 P_{3}\right)
$$

where $Q_{t}$ is the discharge as in equation (1) and $P_{3}$ is the maximum 3-hr rainfall amount.

We then selected four flood events during the disturbed period to estimate the drainage area of the upstream small reservoirs and check dams based on equation (1) (table 6). Since flood peak often occurred approximately 3 or 4 hrs after the maximum 3 hr-maximum rainfall in Wangkuai reservoir watershed during the undisturbed period and it delayed after the construction of check dams, the calculated flood discharge based on equation (2) was compared with the discharge $3 \mathrm{hrs}$ after the maximum $3-\mathrm{hr}$ rainfall, and $A_{r} / A$ was then estimated by equation (1). The $A_{r} / A$ values were different for each selected flood event, but the differences were small, and we chose the mean $34.6 \%$ as the $A_{r} / A$ value. So the drainage area of the upstream small reservoirs and check dams was $1304 \mathrm{~km}^{2}$ which is larger than that of the small reservoirs $\left(460 \mathrm{~km}^{2}\right)$, so the result was considered reasonable.

\subsection{Effects of upstream check dams and reservoirs on medium and small design floods}

Since large number of check dams and several small reservoirs were built during 1980-2000, the observed flood data during 1956-2008 were non-stationary and could not be used for frequency analysis directly. The flood processes during the undisturbed period (before 1979) should be reconstructed under current conditions affected by check dams and small reservoirs. The methods were described in section 3.2 in detail. We selected all the flood events during the undisturbed period to estimate the flood processes under current conditions. The first largest flood peak in a year during the undisturbed period might be the second largest one under current conditions in the same year, and this was the case for the flood event that occurred on July 10, 1958. The flood peak on July 10, 1958 was the largest in this year with $587.0 \mathrm{~m}^{3} / \mathrm{s}$, but under current conditions it was $405.2 \mathrm{~m}^{3} / \mathrm{s}$. Another flood event occurred in the same year on July 16 with a flood peak of $580.0 \mathrm{~m}^{3} / \mathrm{s}$, but it was $441.7 \mathrm{~m}^{3} / \mathrm{s}$ under current conditions. Hence, in this year the flood peak of $441.7 \mathrm{~m}^{3} / \mathrm{s}$ was selected for flood frequency analysis. Additionally, the flood peak of several flood events during the undisturbed period were not affected by check dams and small reservoirs, such as the flood events that occurred on August 4, 1956, August 7, 1959 and August 7, 1963. This was due to the large amount of surface runoff before flood peak that could fill up the upstream check dams and small reservoirs. However, the recalculated time series were nonstationary in a strict sense, because the check dams were constructed gradually during 1980-2008, but the assumption was that the number of check dams in 1980 and 2008 were the same because the change point was in 1979.

The Pearson III distribution function was adopted to fit the empirical frequency of the reconstructed annual maximum flood data because it was used for the design of hydraulic structures in China. Maximum flood peak and flood volumes for different days were selected to perform a frequency analysis, and the results of the frequency analysis for medium and small flood events are shown in figure 5 and table 7 . Compared with the currently used design flood, peak discharges and volumes decreased. With flood frequency higher, design flood peak decreased by a larger percentage when taking into account non-stationarity, from $4.1 \%$ (200-year return period) to $22.0 \%$ (10-year return period). The declined design flood volumes showed the same tendency as design flood peak, decreasing from 3.0\% (200-year return period) to $12.7 \%$ (10-year return period) for $1 \mathrm{~d}$ design flood volume. For $3 \mathrm{~d}$ and $6 \mathrm{~d}$ design flood volumes, the decreased percentages were smaller than those for 1d design flood volumes for 10-200 year return period floods. 


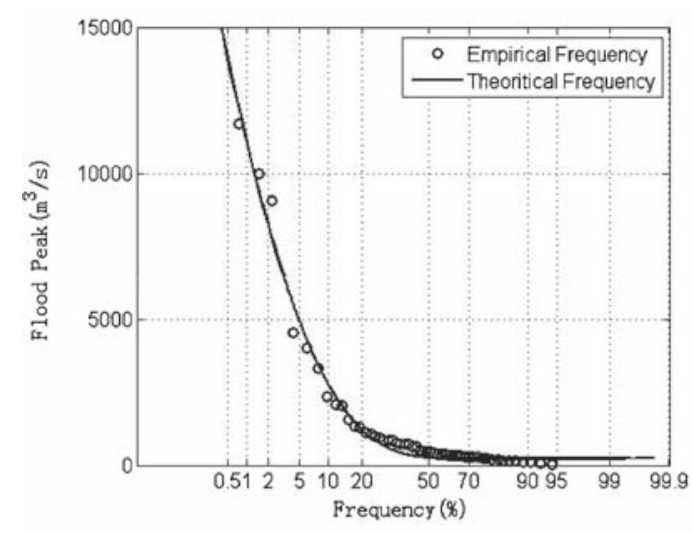

(a) Flood peak frequency

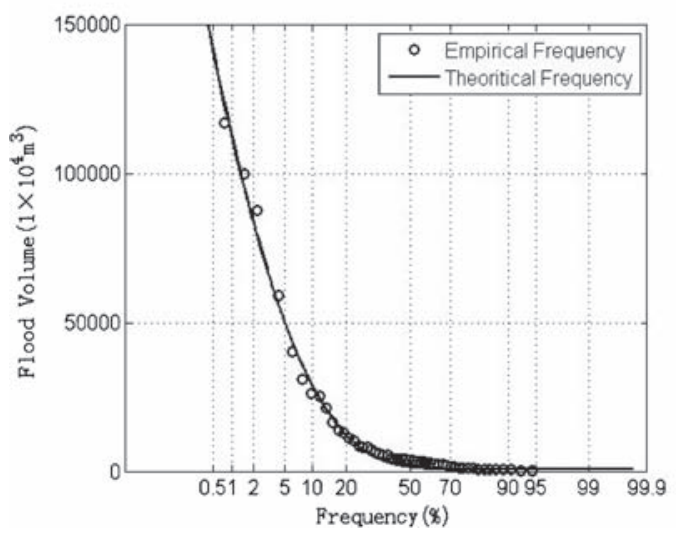

(c) $3 \mathrm{~d}$ flood volume frequency

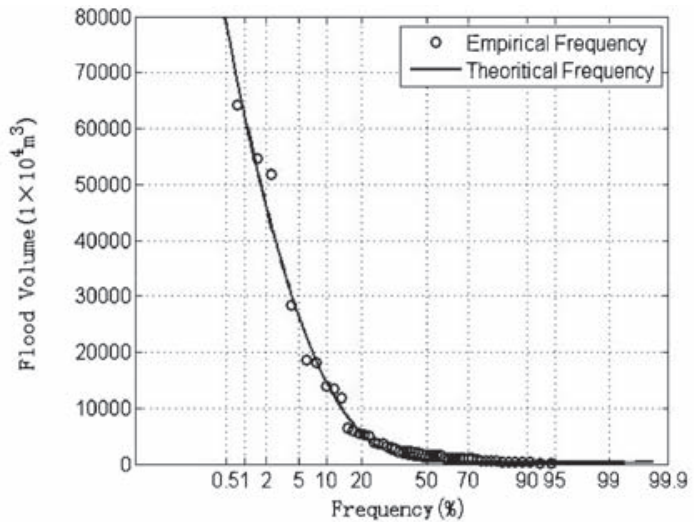

(b) $1 \mathrm{~d}$ flood volume frequency

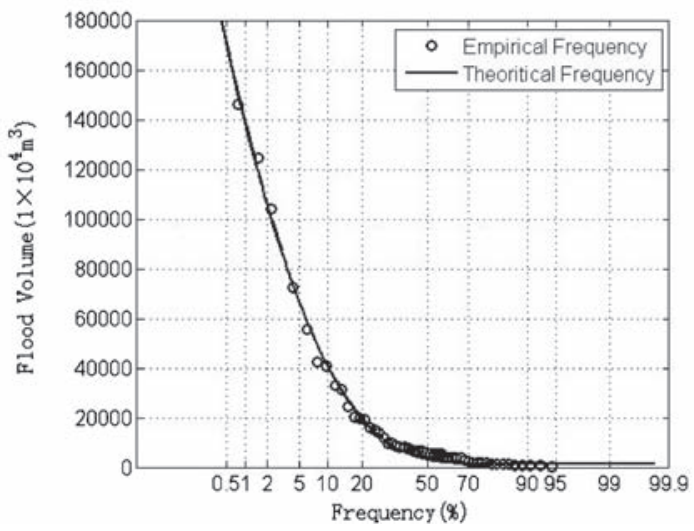

(d) 6 d flood volume frequency

Figure 5. Frequency analysis for medium and small flood events under current conditions.

Table 7. The modified medium and small design floods under current conditions and comparison with the currently used design flood.

\begin{tabular}{|c|c|c|c|c|c|c|c|c|}
\hline \multirow{3}{*}{$\begin{array}{l}\text { Return } \\
\text { period } \\
(y r)\end{array}$} & \multicolumn{2}{|c|}{ Peak discharge } & \multicolumn{6}{|c|}{ Volume $\left(10^{8} \mathrm{~m}^{3}\right)$} \\
\hline & \multirow[b]{2}{*}{$\begin{array}{l}\text { Values } \\
\left(\mathrm{m}^{3} / \mathrm{s}\right)\end{array}$} & \multirow[b]{2}{*}{$\begin{array}{c}\text { Change } \\
(\%)\end{array}$} & \multicolumn{2}{|c|}{$1 d$} & \multicolumn{2}{|c|}{$3 \mathrm{~d}$} & \multicolumn{2}{|c|}{$6 \mathrm{~d}$} \\
\hline & & & $\begin{array}{c}\text { Values } \\
\left(10^{8} \mathrm{~m}^{3}\right)\end{array}$ & $\begin{array}{c}\text { Change } \\
(\%)\end{array}$ & $\begin{array}{c}\text { Values } \\
\left(10^{8} \mathrm{~m}^{3}\right)\end{array}$ & $\begin{array}{c}\text { Change } \\
(\%)\end{array}$ & $\begin{array}{c}\text { Values } \\
\left(10^{8} \mathrm{~m}^{3}\right)\end{array}$ & $\begin{array}{c}\text { Change } \\
(\%)\end{array}$ \\
\hline 200 & 13930 & -4.1 & 7.82 & -3.0 & 13.94 & -0.8 & 16.87 & -0.1 \\
\hline 100 & 11020 & -6.1 & 6.15 & -3.9 & 11.08 & -1.9 & 13.64 & -0.3 \\
\hline 50 & 8236 & -9.1 & 4.56 & -5.4 & 8.34 & -3.6 & 10.51 & -1.5 \\
\hline 20 & 4965 & -13.9 & 2.66 & -8.3 & 5.02 & -7.2 & 6.66 & -3.9 \\
\hline 10 & 2768 & -22.0 & 1.45 & -12.7 & 2.84 & -12.6 & 4.07 & -6.9 \\
\hline
\end{tabular}

\subsection{Catastrophic design flood modification under current conditions}

When meeting catastrophic flood events, such as 1000-year return period or larger floods, the upstream check dams and small hydraulic structures are destroyed, and the water stored is re-routed downstream to the Wangkuai reservoir. Since the locations of the large number of check dams on the river were unknown, a onedimensional hydrodynamic model was difficult to establish. On the basis of currently used design flood hydrographs, the surface runoff generated on the $A_{r}$ area was stored in the check dams and small reservoirs until they were filled up. It was assumed that as design flood peak occurred, the check dams and small reservoirs would be destroyed, and that the water stored in them were routed to the Wangkuai reservoir using unit hydrograph. The flood peak generated by the water stored in check dams and small hydraulic structures was assumed to meet the currently used design flood peak, and 


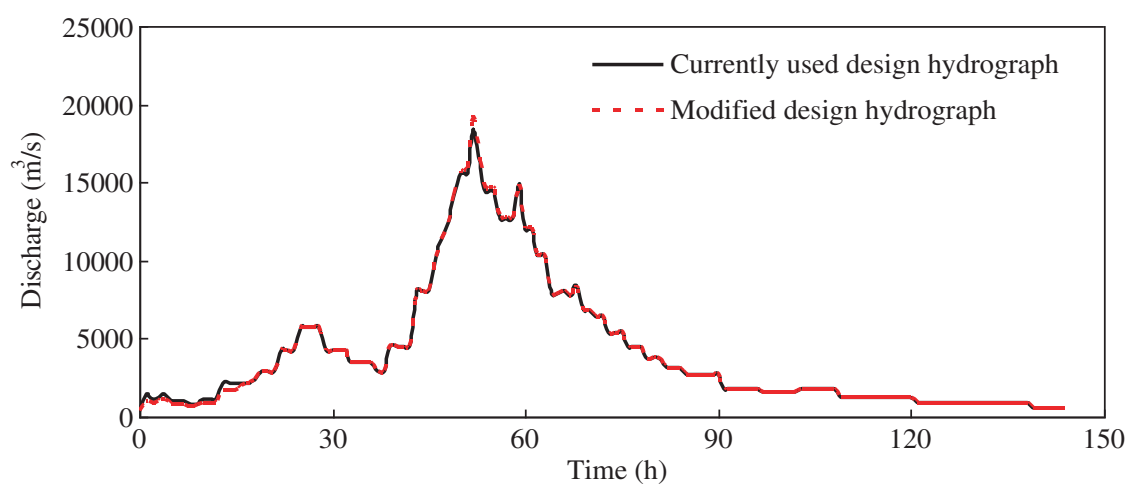

(a) 500 year return period design flood hydrograph

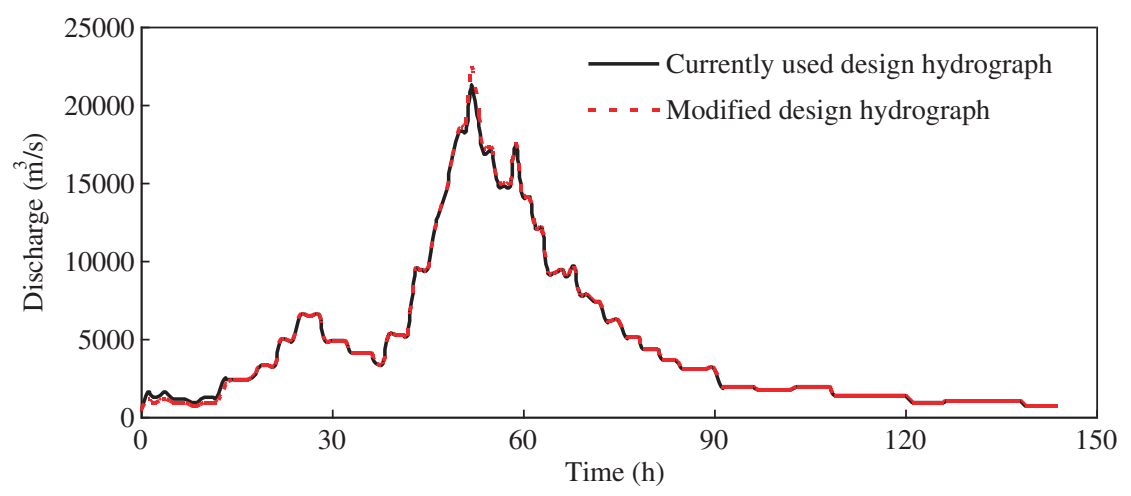

(b) 1000 year return period design flood hydrograph

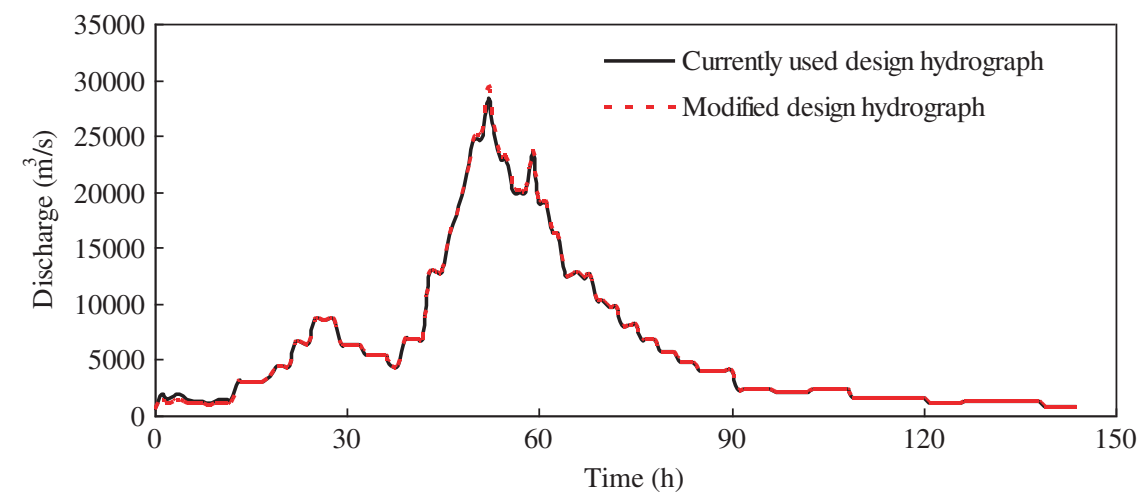

(c) 5000 year return period design flood hydrograph

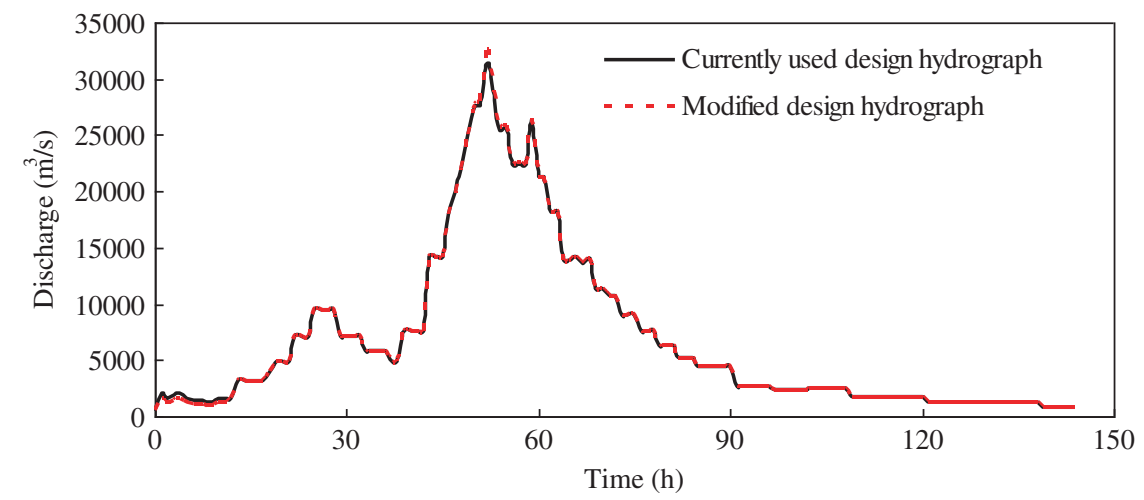

(d) 10000 year return period design flood hydrograph

Figure 6. The modified catastrophic design flood hydrographs. 
new larger design flood hydrographs were determined. The unit hydrograph was calculated using the observed largest flood during the period of 1956-2008. The largest flood during this period occurred on August 7, 1963. The modified large design flood hydrographs are shown in figure 6 .

At the beginning of the modified design flood hydrograph, the discharges were lower than the currently used hydrograph. This difference was stored in the upstream check dams and small reservoirs. The peak discharges of the modified design hydrographs with 1000, 5000 and 10000year return periods were $1174.0 \mathrm{~m}^{3} / \mathrm{s}$ higher than the original ones, which resulted from a routing process of water stored in the check dams and small reservoirs after destruction. For design flood with 500-year return period, all the upstream small reservoirs and check dams except the Haiyan reservoir were destroyed. Hence, 367 million $\mathrm{m}^{3}$ stored in the Haiyan reservoir should be excluded, and the modified design peak discharge was $886.0 \mathrm{~m}^{3} / \mathrm{s}$ higher than the original one. In this study, we did not consider the nonlinearity pointed out by some authors (Robinson et al. 1995; Saghafian 2006). If nonlinearity was accounted for, the modified flood peak for 5000- and 10000-year return periods would be higher.

Feng et al. (2013) and Feng and Li (2013) recalculated the design floods for the Wangkuai reservoir by using different statistical methods accounting for non-stationarity. They concluded that the modified design floods were smaller than those which did not take into account nonstationarity for any return period. However, the mechanisms of flood generation for small and catastrophic floods are different in the watersheds with large number of small hydraulic structures. They did not take into account dam break for low frequency flood events which may lead to flood peak increase.

\section{Conclusions}

The effects of large hydraulic structures on downstream flow were easily determined for their known total storage capacities and drainage area, but it was difficult to do so for the large number of small check dams. In this paper, based on the change point detection results of $\mathrm{Li}$ (2013), we presented a new method to update design floods in watersheds affected by a large number of check dams, and some conclusions can be drawn as follows:

- To assess the effects of upstream hydraulic structures on flood processes, the total storage capacities and drainage area should be determined. Because the location and size of each check dam was unknown, a new method was proposed to estimate the total storage capacity and drainage area of upstream small reservoirs and the large number of check dams. The storage capacity of the check dams and small reservoirs upstream was estimated by two similar large flood events that occurred in undisturbed and disturbed periods, respectively. The TSC and TDA were 14.89 million $\mathrm{m}^{3}$ and $1304 \mathrm{~km}^{2}$, respectively. Although there were large number of check dams, we presented a feasible method to estimate their storage capacity and drainage area.

- Due to the difference in routing process between large and medium floods, the design floods with a return period of larger than 500 years and 10-200 years were calculated by different methods. The design floods for 10-200 year return periods were obtained by frequency analysis using the recalculated stationary flood time series. The derived design flood peaks and volumes were lower than those of the currently used design hydrograph, which did not account for non-stationarity.

- For catastrophic flood events of 1000 10000 years return period, all the check dams and small hydraulic structures were assumed to be destructed. This assumption was made on the basis of the flood control standard of the hydraulic structures, which states that the design standard of those with storage capacity of 100 1000 million $\mathrm{m}^{3}$ was 300 500 year return period (The Ministry of Water Resources of the People's Republic of China, 1994). The recalculated design flood peak was $1174.0 \mathrm{~m}^{3} / \mathrm{s}$ higher than the original ones. For design floods of 500 -year return periods, all of the small hydraulic structures except the Haiyan reservoir were assumed to be destructed. When destructed, the water stored in the small reservoirs was routed to the Wangkuai reservoir by the same unit hydrograph based on the linear assumption of unit hydrograph, and the modified design peak discharge was 886.0 $\mathrm{m}^{3} / \mathrm{s}$ higher than the original one. The managers should make policies to adopt changes in design floods for flood control.

\section{Acknowledgements}

This work was supported by National Natural Science Foundation of China (No. 51209157). We are grateful to Arun Ravindranath of the CUNY (City University of New York) City College for his valuable advice on the study. We also express our thanks to Hydrology and Water Resource Survey Bureau of Hebei Province for providing the hydrometeorological data. 


\section{References}

Archer D and Newson M 2002 The use of indices of flow variability in assessing the hydrological and instream habitat impacts of upland afforestation and drainage; J. Hydrol. $268244-258$.

Ayalew T B, Krajewski W F and Mantilla R 2014 Connecting the Power-law scaling structure of peak-discharges to spatially variable rainfall and catchment physical properties; Adv. Water Resour. 71 32-43.

Carrivick J L 2007 Hydrodynamics and geomorphic work of Jokulhlaups (glacial outburst floods) from Kverkfjoll volcano, Iceland; Hydrol. Process. 21 725-740.

Carrivick J L 2010 Dam break-outburst flood propagation and transient hydraulics: A geoscience perspective; $J$. Hydrol. $380338-355$.

Cunderlik J M and Burn D H 2003 Non-stationary pooled flood frequency analysis; J. Hydrol. 276 210-223.

Costa M H, Botta A and Cardille J A 2003 Effects of large-scale changes in land cover on the discharge of the Tocantins River, southeastern Amazonia; J. Hydrol. 283 206-217.

Cox D R, Isham V S and Northrop P J 2002 Floods: Some probabilistic and statistical approaches; Phil. Trans. Roy. Soc. London, Ser. A 360 1389-1408.

Feng P and Li X 2013 Bivariate frequency analysis of nonstationary flood time series based on Copula methods; J. Hydraul. Eng. 44 1137-1147.

Feng P, Zeng H and Li X 2013 Non-stationary flood frequency analysis based on mixed distribution; J. Tianjin University 46 298-303.

Fitzhugh T W and Vogel R M 2010 The impact of dams on flood flows in the United States; River Res. Appl. 27 $1192-1215$.

Genz F and Luz L D 2014 Distinguishing the effects of climate on discharge in a tropical river highly impacted by large dams; Hydrol. Sci. J. 57 1020-1034.

Gilroy K L and McCuen R H 2012 A nonstationary flood frequency analysis method to adjust for future climate change and urbanization; J. Hydrol. 414 40-48.

Graf W L 2006 Downstream hydrologic and geomorphic effects of large dams on American rivers; Geomorphology $79336-360$.

Gupta V K, Troutman B M and Dawdy D R 2007 Towards a nonlinear geophysical theory of floods in river networks: An overview of 20 years of progress; Nonlinear Dyn. I Geosci., pp. 121-151.

Gupta V K, Mantilla R and Troutman B M et al. 2010 Generalizing a nonlinear geophysical flood theory to mediumsized river networks; Geophys. Res. Lett. 37 L11402, doi: 10.1029/2009GL041540.

Hsieh H M, Luo C R and Yang J C et al. 2013 Numerical study of the effects of check dams on erosion and sedimentation in the Pachang river; Int. J. Sedim. Res. 28 $304-315$.

Katz R W, Partang M B and Naveau P 2002 Statistics of extremes in hydrology; Adv. Water Resour. $251287-$ 1304.

Khaliq M N, Ouarda T B M J and Ondo J C et al. 2006 Frequency analysis of a sequence of dependent and/or nonstationary hydro-meteorological observations: A review; J. Hydrol. 329 534-552.

Lajoie F, Assani A A and Roy A G et al. 2007 Impacts of dams on monthly flow characteristics, the influence of watershed size and seasons; J. Hydrol. 334 423439.

Li X 2013 Flood analysis and calculation based on nonstationary flood time series; Tianjin University, Tianjin.
Magilligan F J and Nislow K H 2005 Changes in hydrological regime by dams; Geomorphology 71 61-78.

Matteau M, Assani A A and Mesfioui M 2009 Application of multivariate statistical analysis methods to the dam hydrologic impact studies; J. Hydrol. 371 120-128.

Milly $\mathrm{P}$ C D, Betancourt J and Falkenmark $\mathrm{M}$ et al. 2008 Stationarity is dead: Whither water management? Science 319 573-574.

Niehoff D, Fritsch U and Bronstert A 2002 Land-use impacts on storm-runoff generation: Scenarios of land use change and simulation of hydrological response in a meso-scale catchment in SW-Germany; J. Hydrol. 267 80-93.

Nirupama N and Simonovic S P 2007 Increase of flood risk due to urbanisation: A Canadian example; Natural Hazards 40 25-41.

Ogden F L and Dawdy D R 2003 Peak discharge scaling in small Hortonian watershed; J. Hydrol. Eng. 8 64-73.

Onema J K, Mazvimavi D and Love D et al. 2006 Effects of selected dams on river flows of Insiza river, Zimbabwe; Physics and Chemistry of the Earth 31 870-875.

Ott B and Uhlenbrook S 2004 Quantifying the impact of land-use changes at the event and seasonal time scale using a process-oriented catchment model; Hydrol. Earth Syst. Sci. 8 62-78.

Richter B D, Baumgartner J V and Wigington R et al. 1997 How much water does a river need? Freshwater Biology 37 231-249.

Robinson J S, Sivapalan M and Snell J D 1995 On the relative roles of hillslope processes, channel routing, and network geomorphology in the hydrologic response of natural catchments; Water Resour. Res. 31 3089-3101.

Robinson M, Cognard-Plancq A L and Cosandey C et al. 2003 Studies of the impact of forests on peak flows and baseflows: A European perspective; Forest Ecol. Manag. 186 85-97.

Saghafian B 2006 Nonlinear transformation of unit hydrograph; J. Hydrol. 330 596-603.

Smith S V, Renwick W H and Bartley J D et al. 2002 Distribution and significance of small, artificial water bodies across the United States landscape; Sci. Total Environ. $29921-36$.

Strupczewski W G, Singh V P and Feluch W 2001a Nonstationary approach to at-site flood frequency modeling I. Maximum likelihood estimation; J. Hydrol. 248 $123-142$.

Strupczewski W G, Singh V P and Mitosek H T 2001b Non-stationary approach to at-site flood frequency modeling III. Flood analysis of Polish rivers; J. Hydrol. 248 152-167.

Tarolli P, Borga M and Morin E et al. 2012 Analysis of flash flood regimes in the north-western and south-eastern Mediterranean regions; Natural Hazards and Earth Syst. Sci. 12 1255-1265.

The Ministry of Water Resources of the People's Republic of China 1994 Standard for flood control (GB50201-94).

Walder J S and Costa J E 1996 Outburst floods from glacierdammed lakes: The effect of mode of lake drainage on flood magnitude; Earth Surface Processes and Landforms 21 701-723.

Wang J C, Yu H and Zhao J 2000 Relation of design flood peak discharge rate to collecting area in Nenjiang river basin; J. Heilongjiang Hydraulic Engineering College $\mathbf{2 7}$ 15-16.

Wellmeyer J L, Slattery M C and Phillips J D 2005 Quantifying downstream impacts of impoundment on flow regime and channel planform, lower Trinity river, Texas; Geomorphology 69 1-13.

$\mathrm{Yu}$ K and Moyeed R A 2001 Bayesian quantile regression; Statistics and Probability Letters 54 437-447. 
Yu K, Lu Z and Stander J 2003 Quantile regression: Applications and current research area; The Statistician $\mathbf{5 2}$ 331-350.

Zahar Y, Ghorbel A and Albergel J 2008 Impacts of large dams on downstream flow conditions of rivers: Aggradation and reduction of the Medjerda channel capacity downstream of the Sidi Salem dam (Tunisia); J. Hydrol. $351318-330$.
Zhang J Z and Mao H H 2012 Study on methods for modification of design flood under condition of change in underlying surface; Water Resour. Hydropower Eng. 43 $1-5$.

Zimmerman J K H, Letcher B H and Nislow K H et al. 2010 Determining the effects of dams on subdaily variation in river flows at a whole-basin scale; River Res. Appl. 26 1246-1260.

MS received 25 March 2015; revised 9 December 2015; accepted 1 January 2016

Corresponding editor: SHIVAM TRIPATHI 